\title{
Effects of Substituents on the Stabilities of Phosphonyl Radicals and their Hydroxyphosphinyl Tautomers
}

\author{
Elizabeth H. Krenske and Michelle L. Coote* \\ ARC Centre of Excellence for Free Radical Chemistry and Biotechnology, Research School of Chemistry, \\ The Australian National University, Canberra ACT 0200, Australia
}

Received: March 25, 2007; In Final Form: June 13, 2007

\begin{abstract}
High-level ab initio quantum chemical methods have been used to calculate the radical stabilization energies (RSEs) of phosphonyl radicals $\mathrm{XYP}(=\mathrm{O}) \cdot$ bearing a range of substituents $\mathrm{X}$ and $\mathrm{Y}$. The main influences on these radicals' stabilities are $\sigma$-effects. Due to the high positive charge on phosphorus, $\sigma$-withdrawal is destabilizing, and $\sigma$-donation is stabilizing. The pyramidal geometry at phosphorus minimizes the effect of stabilization by $\pi$-delocalization, while the potentially stabilizing effect of lone-pair donation is outweighed by concomitant $\sigma$-withdrawal. Thus, the calculated RSEs of phosphonyl radicals $\mathrm{XHP}(=\mathrm{O}) \cdot$ increase in the order $\mathrm{X}=\mathrm{F}<\mathrm{Me}_{3} \mathrm{~N}^{+}<\mathrm{MeO}<\mathrm{CF}_{3}<{ }^{t} \mathrm{Bu}<\mathrm{Me}_{2} \mathrm{~N}<\mathrm{NC}<\mathrm{H}<\mathrm{Ph}<\mathrm{MeS}<\mathrm{Me}_{3} \mathrm{Si}$. The tautomeric hydroxyphosphinyl radicals $\mathrm{X}(\mathrm{OH}) \mathrm{P} \cdot$ exhibit a different set of substituent effects, with RSEs increasing in the order $\mathrm{X}=\mathrm{CF}_{3}<\mathrm{Me}_{2} \mathrm{~N}<\mathrm{Me}_{3} \mathrm{~N}^{+}<\mathrm{MeO}<{ }^{t} \mathrm{Bu}<\mathrm{H}<\mathrm{MeS}<\mathrm{Me}_{3} \mathrm{Si}<\mathrm{F}<\mathrm{NC}<\mathrm{Ph}$. In these radicals, both the $\sigma$ - and $\pi$-properties of the $\mathrm{X}$ substituent influence stability, in tandem with those of the $\mathrm{OH}$ group. A comparison of the absolute enthalpies of isomeric phosphonyl and hydroxyphosphinyl radicals indicates that the hydroxyphosphinyl radicals $\mathrm{X}(\mathrm{OH}) \mathrm{P} \cdot$ are more stable than the phosphonyl radicals $\mathrm{XYP}(=\mathrm{O}) \cdot$. This is not a common situation in phosphorus chemistry. It is primarily attributed to the greater phosphorus p character of the singly occupied molecular orbital (SOMO) in the hydroxyphosphinyl radicals compared with the phosphonyl tautomers. As in closed-shell phosphorus species, the magnitude of the effect is modulated by the electronegativity of the substituent $\mathrm{X}$.
\end{abstract}

\section{Introduction}

Phosphorus-based radicals encompass a range of structural classes, of which the most well-known are the phosphoranyl radicals $\mathrm{R}_{4} \mathrm{P} \cdot$, phosphinyl radicals $\mathrm{R}_{2} \mathrm{P} \cdot$, and phosphonyl radicals $\mathrm{R}_{2} \mathrm{P}(=\mathrm{O}) \cdot$. These have been extensively studied over many decades, both by experimental ${ }^{1}$ and computational ${ }^{2}$ means. Of the various classes of phosphorus-based radicals, phosphonyl radicals are of particular interest in organic synthesis, where their applications include both the formation of phosphoruscarbon bonds (taking advantage of their facile addition reactions with alkenes) and the mediation of radical chain reactions as an alternative to tin- or silicon-based approaches. ${ }^{3,4}$ Phosphonyl radicals are often generated by abstraction of hydrogen from the parent phosphorus hydrides, the most popular examples in current use being the dialkylphosphine oxide $\mathrm{Et}_{2} \mathrm{P}(=\mathrm{O}) \mathrm{H}$ and hypophosphite salts such as (1-ethylpiperidinium) $\mathrm{H}_{2} \mathrm{PO}_{2}$.

Electron spin resonance measurements ${ }^{5,6}$ have shown that phosphonyl radicals have a pyramidal structure (1), in which the singly occupied orbital possesses significant phosphorus 3 s character. Kinetic measurements ${ }^{7}$ have indicated that phosphonyl radicals of the type $\operatorname{Ar}_{2} \mathrm{P}(=\mathrm{O}) \cdot$, where $\mathrm{Ar}$ is phenyl, $o$ or $p$-tolyl, or $o$-anisyl, add to $\mathrm{C}=\mathrm{C}$ double bonds with rate constants on the order of $10^{6}$ to $10^{7} \mathrm{M}^{-1} \mathrm{~s}^{-1}$ (room temperature), the rate constants increasing in the order $\mathrm{CH}_{2}=\mathrm{CH}(\mathrm{CN})<$ $\mathrm{CH}_{2}=\mathrm{C}\left(\mathrm{CH}_{3}\right)(\mathrm{CN})<\mathrm{CH}_{2}=\mathrm{CH}(\mathrm{Ph})$. This rapid addition to double bonds has on rare occasion been problematic when phosphonyl radicals have been used as chain carriers. Thus, Barton et al. found ${ }^{8,9}$ that the radical anion $\mathrm{HPO}_{2}{ }^{-}$(derived

* Corresponding author. E-mail: mcoote@rsc.anu.edu.au. from hypophosphite anion) added rapidly to the $\mathrm{C}=\mathrm{C}$ bond of alkene $\mathbf{3}$, necessitating the use of a sacrificial alkene in the conversion $\mathbf{2} \rightarrow \mathbf{3}$ (Scheme 1). On the other hand, however, Gonzalez Martin et al. ${ }^{10}$ found that the use of hypophosphitemediated methodology gave good yields of cyclized products in intramolecular additions of aryl radicals (e.g., Scheme 2). Moreover, Jang et al. ${ }^{11}$ successfully used hypophosphite methodology for intermolecular additions of alkyl radicals onto electron-poor terminal alkenes.

In this paper, we wish to consider the effects of substituents on the properties of phosphonyl radicals. This work builds on the results of a number of previous theoretical studies in various laboratories, which have provided information on the structures and stabilities of a range of phosphorus-based radicals and the ways in which they may be modulated by substituents. ${ }^{2} \mathrm{We}$ report here the results of high-level quantum chemical calculations on the electronic structures and radical stabilization energies (RSEs) of radicals $\mathrm{XYP}(=\mathrm{O}) \cdot$

It is also well-known in phosphorus chemistry that species of the type $\mathrm{XYP}(=\mathrm{O}) \mathrm{H}$ exist in tautomeric equilibrium with species XYP-OH. ${ }^{12}$ In principle, a similar tautomerism could operate for phosphonyl radicals, if one of the substituents on phosphorus is a hydrogen atom: $\operatorname{XHP}(=\mathrm{O}) \cdot$. The corresponding tautomeric radicals are the hydroxyphosphinyl radicals $\mathrm{X}(\mathrm{OH}) \mathrm{P}$. To our knowledge, a systematic computational study of the effects of substituents in hydroxyphosphinyl radicals has not previously appeared in the literature. Therefore, in order to probe the significance of the tautomerism, we have also calculated the stabilities of various hydroxyphosphinyl radicals. 


\section{SCHEME 1}

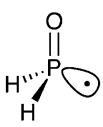

1

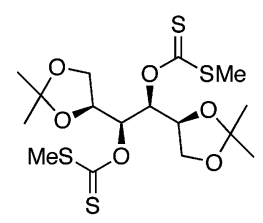

2

SCHEME 2
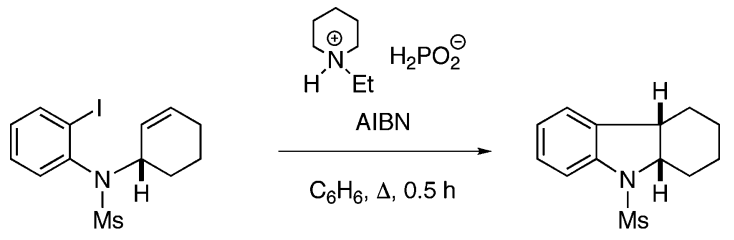

$78 \%$

\section{Computational Procedures}

Standard ab initio molecular orbital theory ${ }^{13}$ and density functional theory ${ }^{14}$ calculations were carried out using GAUSSIAN $03^{15}$ and MolPro 2006.1. ${ }^{16}$ Geometries were optimized at the B3LYP/6-31+G(d) level of theory, with use of extensive conformational searching to identify the global minimum-energy conformer (as opposed to merely a local minimum) of each species. Vibrational frequencies were calculated at the same level and used to confirm the nature of the stationary points. Because scale factors for the B3LYP/6$31+\mathrm{G}(\mathrm{d})$ frequencies were not available, those for the B3LYP/ 6-31G(d) level were used instead when calculating the zeropoint vibrational energy corrections. ${ }^{17}$

Improved energies for all species were obtained at a level of theory related to the G3(MP2)-RAD procedure, which we have denoted $^{18}$ as G3(MP2)-RAD(+). G3(MP2)-RAD is a high-level composite procedure that attempts to reproduce coupled-cluster $[\operatorname{CCSD}(\mathrm{T})]$ energies with a large triple- $\zeta$ basis set by using additivity corrections carried out at the RMP2 level. The G3(MP2)-RAD (+) method differs from G3(MP2)-RAD in that the geometries, frequencies, $\mathrm{U}(\mathrm{R}) \mathrm{CCSD}(\mathrm{T})$ single-point energy, and $\mathrm{R}(\mathrm{O}) \mathrm{MP} 2$ single-point energy are calculated at the B3LYP/ 6-31+G(d) level rather than at the B3LYP/6-31G(d) level. The G3(MP2)-RAD method has previously been demonstrated to provide accurate absolute values of the heats of formation for a large test set of radical and nonradical species (MAD $4.7 \mathrm{~kJ}$ $\left.\mathrm{mol}^{-1}\right) .{ }^{19}$ Moreover, it has previously been shown to provide accurate values for the RSEs of carbon-centered radicals ${ }^{20,21}$ and nitrogen-centered radicals, ${ }^{22}$ as well as for the kinetics and thermodynamics of a variety of radical reactions. ${ }^{23-27} \mathrm{We}$ here test the performance of G3(MP2)-RAD and G3(MP2)$\mathrm{RAD}(+)$, as well as various other methods, for calculating the RSEs of a range of phosphorus radicals, with use of the W1 procedure as a benchmarking level. As described below, this led us to carry out our examination of substituent effects at the G3(MP2)-RAD(+) level. The incorporation of diffuse functions was deemed advantageous, because it provides results that will be directly comparable with those on anionic species to be reported elsewhere ${ }^{28}$ in our closely related work on phosphorusbased radical chain carriers.
The RSE of a radical $\mathrm{R} \cdot$ is here defined in the usual manner, that is, the value of $\Delta H$ at $0 \mathrm{~K}$ (including zero-point energy correction) for the hydrogen-transfer reaction $\mathrm{R} \cdot+\mathrm{CH}_{4} \rightarrow \mathrm{R}-\mathrm{H}$ $+\mathrm{CH}_{3} \cdot{ }^{29}$ In a previous study of phosphoranyl radicals of the type $\mathrm{Me}_{3} \mathrm{XP} \cdot{ }^{2 \mathrm{j}}$ it was previously noted that the use of a hydrogen-transfer reaction to measure radical stability gave results that were inconsistent with the expected substituent effects in the radicals and instead reflected the stabilities of the closed-shell parent hydrides. A better measure of the radicals' stabilities in that case was gained through use of a $\mathrm{P}-\mathrm{Me}$ transfer reaction. In the current work, however, we have adhered to the use of a hydrogen-transfer reaction. Although the RSEs defined in this way will be a function of several factors-(1) the difference between the stabilities of the phosphorus-centered radical and the carbon-centered radical $\mathrm{CH}_{3}{ }^{\circ}$, and (2) the difference between the stabilities of the $\mathrm{P}-\mathrm{H}$ parent compound and $\mathrm{CH}_{4}$-we nevertheless find that its use is appropriate here. First, it provides a constant point of reference for comparing the differences in $\mathrm{P}-\mathrm{H}$ bond strengths of both the three- and four-coordinate phosphorus parent species considered in this work. Second, as will be seen below, we find that it provides meaningful insights into substituent effects for both the twoand three-coordinate phosphorus-based radicals, without being confounded by effects on the closed-shell parent hydrides. Finally, because our main aim in this work is to gain information that will help to predict how well different phosphorus-based radicals will perform as mediators in radical chain processes, a definition based on $\mathrm{P}-\mathrm{H}$ bond strengths is valuable.

To assist in the qualitative rationalization of results, natural charges and spin densities were calculated at the B3LYP/6$311+\mathrm{G}(3 \mathrm{df}, 2 \mathrm{p})$ level of theory using the geometries obtained at the B3LYP/6-31+G(d) level, with the aid of the natural bond orbital (NBO) analysis program ${ }^{30}$ in conjunction with Gaussian. An analysis of solvent effects was also carried out using the polarizable continuum model as implemented in Gaussian.

Optimized geometries for all radicals and closed-shell hydrides are provided in the form of Gaussian archive entries in the Supporting Information.

\section{Results and Discussion}

Choice of Computational Method. Earlier studies of phosphorus-containing radicals $\mathrm{s}^{2 \mathrm{f}, 2 \mathrm{~h}}$ have indicated that calculated geometries are sensitive to the level of theory used for geometrical optimization. This has a follow-on effect in the calculation of experimentally determinable parameters such as electron paramagnetic resonance (EPR) hyperfine coupling constants. For example, Cramer and $\operatorname{Lim}^{2 \mathrm{f}}$ found that the hyperfine coupling constants calculated for a wide range of phosphorus radicals at the MP2-fu/6-311G(d,p) level were in good agreement with experiment when $\mathrm{HF} / 6-31 \mathrm{G}(\mathrm{d}, \mathrm{p})$ geometries were used but in poor agreement when MP2-fu/6-31G(d,p) geometries were used. In Table 1, therefore, we provide the pertinent geometrical parameters for two prototypical radicals of relevance to the present study, $\mathrm{H}_{2} \mathrm{P}(=\mathrm{O}) \cdot$ and $\mathrm{H}_{2} \mathrm{P} \cdot$, as calculated at a variety of levels of theory. Experimental gasphase geometrical data are available for both of these radicals. ${ }^{31,32}$

For the radical $\mathrm{H}_{2} \mathrm{P}(=\mathrm{O}) \cdot$, gas-phase structural data are available from microwave spectroscopy measurements ${ }^{31}$ and are included in Table 1. Of the levels of theory included in Table 1 , the only level giving geometrical parameters that are markedly different from experiment is $\mathrm{HF} / 6-31 \mathrm{G}(\mathrm{d})$. This overestimates the $\mathrm{P}=\mathrm{O}$ bond length by $0.1 \AA$ and underestimates the $\mathrm{O}-\mathrm{P}-\mathrm{H}$ angle by $12^{\circ}$. The best match with experimental data is provided 
TABLE 1: Geometrical Parameters Calculated at Various Levels of Theory for the Radicals $\mathrm{H}_{2} \mathrm{P}(=\mathrm{O}) \cdot$ and $\mathrm{H}(\mathrm{OH}) \mathrm{P}$.

\begin{tabular}{|c|c|c|c|c|c|c|}
\hline \multirow[t]{2}{*}{ Level of Theory } & \multicolumn{4}{|c|}{$\begin{array}{c}\prod_{\mathrm{H}} \\
\mathrm{H} \\
\left({ }^{2} \mathrm{~A}^{\prime}\right)\end{array}$} & \multicolumn{2}{|c|}{$\begin{array}{c}\left.\mathrm{H}^{-\dot{\mathrm{P}}}\right\rangle_{\mathrm{H}} \\
\left({ }^{2} \mathrm{~B}_{1}\right)\end{array}$} \\
\hline & $\mathrm{P}=\mathrm{O}(\AA)$ & $\mathrm{P}-\mathrm{H}(\AA)$ & $\mathrm{O}-\mathrm{P}-\mathrm{H}\left({ }^{\circ}\right)$ & $\mathrm{H}-\mathrm{P}-\mathrm{H}\left({ }^{\circ}\right)$ & P-H $(\AA)$ & $\mathrm{H}-\mathrm{P}-\mathrm{H}\left(^{\circ}\right)$ \\
\hline $\mathrm{HF} / 6-31 \mathrm{G}(\mathrm{d})$ & 1.589 & 1.399 & 103.7 & 98.2 & 1.407 & 93.5 \\
\hline B3LYP/6-31G(d) & 1.523 & 1.427 & 113.6 & 100.6 & 1.430 & 91.6 \\
\hline B3LYP/6-31+G(d) & 1.524 & 1.426 & 113.0 & 101.8 & 1.430 & 91.8 \\
\hline B3LYP/6-311G(d,p) & 1.517 & 1.427 & 113.6 & 101.0 & 1.428 & 91.7 \\
\hline B3PW91/6-311G(d,p) & 1.517 & 1.427 & 114.0 & 101.0 & 1.428 & 91.5 \\
\hline MP2/6-31G(d) & 1.497 & 1.415 & 118.5 & 101.6 & 1.419 & 92.6 \\
\hline MP2/6-31G(d,p) & 1.496 & 1.407 & 118.6 & 101.4 & 1.410 & 92.4 \\
\hline QCISD/6-31G(d) & 1.522 & 1.422 & 114.4 & 101.5 & 1.430 & 92.1 \\
\hline B3LYP/cc-pVTZ+1 & 1.497 & 1.421 & 114.0 & 101.9 & 1.422 & 91.7 \\
\hline Experiment $^{a}$ & 1.488 & 1.429 & 115.5 & 102.6 & 1.428 & 91.5 \\
\hline
\end{tabular}

${ }^{a}$ Refs 31 and 32.

by the B3LYP/cc-pVTZ+1 geometry, which is the basis geometry for the W1 method used as our benchmark level of theory below. In general, though, all of the other listed methodsincluding MP2-provide geometries for the $\mathrm{H}_{2} \mathrm{P}(=\mathrm{O}) \cdot$ radical that are comparable to experiment, with bond lengths within $2.5 \%$ and bond angles within $2.6 \%$ of experimental values. Similar qualitative observations are found for the parent phosphinyl radical $\mathrm{H}_{2} \mathrm{P}$.

Moving to substituted systems, greater structural variations are found when comparing different levels of theory. For example, following from the earlier work of Cramer and Lim, ${ }^{2 f}$ who benchmarked geometries according to the hyperfine coupling constants calculated at the MP2-fu/6-311G(d,p) level, we now find that for the radical $\mathrm{Me}_{2} \mathrm{P}(=\mathrm{O}) \cdot$, the use of the B3LYP/6-31+G(d) geometry leads to a marked overestimation of the phosphorus hyperfine coupling constant ( $462 \mathrm{G}$ compared with an experimental ${ }^{33}$ value of $375 \mathrm{G}$ ). In this radical, the $\mathrm{P}=\mathrm{O}$ and $\mathrm{P}-\mathrm{C}$ bond lengths at the B3LYP/6-31+G(d) level are $0.03-0.04 \AA$ longer than at $\mathrm{HF} / 6-31 \mathrm{G}(\mathrm{d})$.

In the present study, we are interested in the relationships between these geometrical variations and the RSEs of phosphorus radicals. Because the calculation of an RSE involves both the radical and its corresponding closed-shell hydride on opposite sides of the equation, it is plausible that geometrical effects will be reduced through cancellation of errors. In Table 2 are provided the RSEs of four prototypical radicals, namely, $\mathrm{H}_{2} \mathrm{P}(=\mathrm{O}) \cdot, \mathrm{H}_{2} \mathrm{P} \cdot, \mathrm{H}_{4} \mathrm{P} \cdot$, and $\mathrm{H}(\mathrm{HO}) \mathrm{P} \cdot$, calculated at a variety of levels of theory.

To our knowledge, experimental data are not available for the RSEs or bond dissociation energies (BDEs) of most of these parent radicals (with the exception of the $\mathrm{H}_{2} \mathrm{P} \cdot$ radical-see below). We have therefore made recourse to $\mathrm{W} 1$ theory $^{34,35}$ as our benchmark level of theory. W1 theory has been demonstrated to provide "kJ accuracy" when assessed against a large test set of gas-phase experimental data and has also proven reliable for a variety of radical reactions such as hydrogenabstraction $^{36}$ and additions to $\mathrm{C}=\mathrm{C}^{37}$ and $\mathrm{C}=\mathrm{S}^{38}$ bonds. The first point to note from Table 2 is that none of the lower levels of theory (entries 1-5) provide reliable RSEs for the four radicals. This includes the QCISD/6-31G(d) level. However, the geometries obtained at the lower levels of theory are in most cases adequate starting points from which reliable improved energies may be obtained through use of G3(MP2)-RAD-based procedures. Entries 6-12 show that when improved energies are calculated on these geometries using the G3(MP2)$\mathrm{RAD}(+)$ method (incorporating scaled ${ }^{17}$ B3LYP/6-31+G(d) zero-point energies), there is good agreement with the W1 RSEs (within $4 \mathrm{~kJ} \mathrm{~mol}^{-1}$ ) and notably little variation stemming from the use of different levels for geometry optimization. One exception to this is found when using HF/6-31G(d) geometries to calculate the RSE of the $\mathrm{H}_{2} \mathrm{P}(=\mathrm{O}) \cdot$ radical. The deficiencies of $\mathrm{HF} / 6-31 \mathrm{G}(\mathrm{d})$ for this radical, including the overestimation of the $\mathrm{P}=\mathrm{O}$ bond length, were noted above; the $\mathrm{P}=\mathrm{O}$ bond in the closed-shell hydride $\mathrm{H}_{3} \mathrm{P}=\mathrm{O}$ does not display the same excessive lengthening.

We therefore conclude that for calculating the RSEs of phosphonyl and phosphinyl radicals, the G3(MP2)-RAD-related procedures offer a reliable approach. Entries 13 and 14 in Table 2 show the difference between the standard G3(MP2)-RAD RSEs and those obtained using our modification G3(MP2)$\mathrm{RAD}(+)$. Both methods provide good approximations of the $\mathrm{W} 1$ energies, the difference between them ranging from 0.8 to $2.1 \mathrm{~kJ} \mathrm{~mol}^{-1}$. Because our present study of substituent effects forms a component of a wider program studying anionic radical chain-transfer agents, we have chosen to use the G3(MP2)$\mathrm{RAD}(+)$ procedure, so as to allow for direct comparisons with future calculations requiring treatment of anions.

A small measure of the accuracy of the G3(MP2)-RAD $(+)$ method for the stabilities of phosphorus-based radicals is provided by comparison of the calculated and experimental RSEs for $\mathrm{PH}_{2} \cdot$. At the G3(MP2)-RAD $(+)$ level of theory the calculated value is $95.4 \mathrm{~kJ} \mathrm{~mol}^{-1}$. An experimental value of $87.2 \pm 2.1 \mathrm{~kJ} \mathrm{~mol}^{-1}$ may be calculated using the experimental ${ }^{39}$ $\mathrm{C}-\mathrm{H}$ BDE of $\mathrm{CH}_{4}\left(432.2 \pm 0.2 \mathrm{~kJ} \mathrm{~mol}^{-1}\right)$ and the experimental ${ }^{39,40} \mathrm{P}-\mathrm{H}$ BDE of $\mathrm{PH}_{3}\left(345.0 \pm 1.9 \mathrm{~kJ} \mathrm{~mol}^{-1}\right)$ (both at $0 \mathrm{~K}$ ). However, the validity of this result is somewhat questionable, for calculation of the RSE using the $0 \mathrm{~K}$ heats of formation listed in the NIST database ${ }^{41}$ leads to a value of $106.3 \mathrm{~kJ} \mathrm{~mol}^{-1}$.

The potential for solvent effects on the radicals' structures and stabilities was assessed by means of polarizable continuum model calculations using various solvents in which phosphonyl radicals are commonly generated. A compilation of data showing the calculated charges, spin densities, and RSEs for the radicals $\mathrm{H}_{2} \mathrm{P}(=\mathrm{O}) \cdot$ and $\mathrm{H}(\mathrm{HO}) \mathrm{P}$ - in various solvent media is given in 
8232 J. Phys. Chem. A, Vol. 111, No. 33, 2007

TABLE 2: RSEs Calculated at Various Levels of Theory for the Radicals $\mathrm{H}_{2} \mathrm{P}(=\mathbf{O}) \cdot \mathrm{H}_{2} \mathrm{P} \cdot \mathrm{H}_{4} \mathrm{P} \cdot$, and $\mathbf{H}(\mathrm{OH}) \mathbf{P}$.

\begin{tabular}{|c|c|c|c|c|c|}
\hline Entry & Level of Theory & 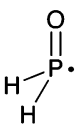 & $\mathrm{H}^{-} \dot{\mathrm{P}}_{-}$ & $\mathrm{H}=\stackrel{\mathrm{P}_{\mathrm{H}}^{\mathrm{I}}}{\mathrm{H}}$ & $\dot{P}_{-}$ \\
\hline 1 & $\mathrm{HF} / 6-31 \mathrm{G}(\mathrm{d})$ & 71.2 & 86.7 & 185.4 & 97.6 \\
\hline 2 & B3LYP/6-31G(d) & 114.9 & 103.7 & 222.0 & 131.4 \\
\hline 3 & B3LYP/6-31+G(d) & 109.3 & 98.5 & 220.8 & 125.8 \\
\hline 4 & MP2/6-31G(d) & 92.2 & 112.2 & 228.5 & 132.7 \\
\hline \multirow[t]{2}{*}{5} & QCISD/6-31G(d) & 102.4 & 107.2 & 225.3 & 128.5 \\
\hline & $\mathrm{G} 3(\mathrm{MP} 2)-\mathrm{RAD}(+) / /^{a}$ & & & & \\
\hline 6 & $\mathrm{HF} / 6-31 \mathrm{G}(\mathrm{d})$ & 55.1 & 95.7 & 206.8 & 116.8 \\
\hline 7 & B3LYP/6-31G(d) & 80.7 & 95.3 & 206.3 & 115.1 \\
\hline 8 & B3LYP/6-311G(d,p) & 81.2 & 95.1 & 206.3 & 114.0 \\
\hline 9 & B3PW91/6-311G(d,p) & 81.9 & 95.0 & 206.1 & 114.1 \\
\hline 10 & $\mathrm{MP} 2 / 6-31 \mathrm{G}(\mathrm{d})$ & 82.2 & 95.5 & 206.2 & 115.5 \\
\hline 11 & MP2/6-31G(d,p) & 81.9 & 95.4 & 204.9 & 114.5 \\
\hline 12 & QCISD/6-31G(d) & 81.6 & 95.5 & 206.8 & 115.2 \\
\hline 13 & G3(MP2)-RAD ${ }^{a}$ & 79.2 & 94.3 & 205.0 & 114.2 \\
\hline 14 & $\mathrm{G} 3(\mathrm{MP} 2)-\mathrm{RAD}(+)^{b}$ & 80.6 & 95.4 & 206.7 & 115.0 \\
\hline 15 & W1 & 84.6 & 93.2 & 203.8 & 114.7 \\
\hline 16 & Experimental & & $\begin{array}{c}87.2 \pm 2.1^{c} \\
106.3^{d}\end{array}$ & & \\
\hline
\end{tabular}

${ }^{a}$ Standard procedure using B3LYP/6-31G(d) geometry. ${ }^{b}$ Standard procedure using B3LYP/6-31+G(d) geometry. ${ }^{c}$ Refs 39 and $40 .{ }^{d}$ Ref 41.

TABLE 3: Effect of Solvent on the Calculated Electronic Structures and Stabilities of Radicals $\mathrm{H}_{2} \mathrm{P}(=\mathrm{O}) \cdot$ and $\mathrm{H}_{(\mathrm{OH}) \mathrm{P} \cdot a}$

\begin{tabular}{|c|c|c|c|c|c|}
\hline Property & Gas-Phase & Cyclohexane & Benzene & Ethanol & Water \\
\hline$\underset{\mathrm{H}}{\stackrel{O}{\mathrm{O}}} \underset{\mathrm{P}}{\mathrm{P}}$ & & & & & \\
\hline Charge on $P$ & 1.043 & 1.051 & 1.052 & 1.062 & 1.063 \\
\hline Charge on $\mathrm{O}$ & -0.898 & -0.919 & -0.921 & -0.950 & -0.952 \\
\hline$\alpha$ Spin density on $\mathrm{P}$ & 0.512 & 0.527 & 0.529 & 0.550 & 0.552 \\
\hline$\alpha$ Spin density on $O$ & 0.389 & 0.376 & 0.374 & 0.355 & 0.354 \\
\hline RSE & 79.8 & 79.3 & 79.2 & 78.4 & 78.3 \\
\hline Charge on $P$ & 0.565 & 0.562 & 0.562 & 0.559 & 0.559 \\
\hline Charge on $\mathrm{O}$ & -0.959 & -0.965 & -0.965 & -0.974 & -0.975 \\
\hline$\alpha$ Spin density on $P$ & 0.912 & 0.911 & 0.911 & 0.909 & 0.908 \\
\hline$\alpha$ Spin density on $O$ & 0.106 & 0.107 & 0.108 & 0.110 & 0.110 \\
\hline RSE & 115.0 & 115.4 & 115.5 & 116.1 & 116.0 \\
\hline
\end{tabular}

${ }^{a}$ Solvent effects calculated using the polarizable continuum model.

Table 3. At the B3LYP/6-31+G(d) level, the geometries of both radicals vary little on going from the gas phase to a solvent medium. For example, the $\mathrm{P}=\mathrm{O}$ bond length of $\mathrm{H}_{2} \mathrm{P}(=\mathrm{O}) \cdot$ increases from $1.524 \AA$ in the gas phase, to $1.525 \AA$ in benzene 


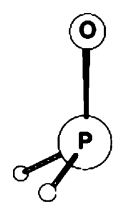

1

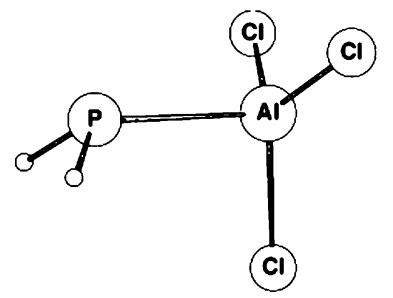

5

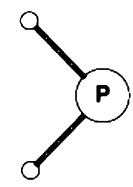

2

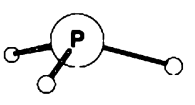

3

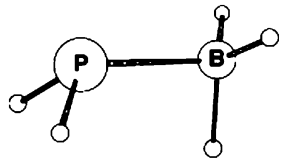

4

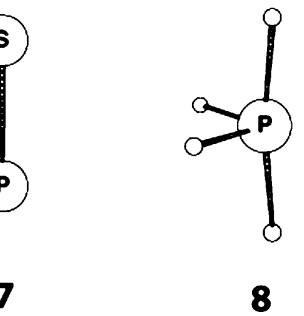

6

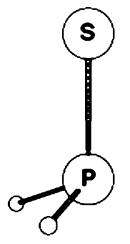

7

Figure 1. Optimized geometries of radicals having different phosphorus bonding modes (obtained at the B3LYP/6-31+G(d) level).

or cyclohexane, and to $1.528 \AA$ in ethanol or water. In all four solvents, the radical $\mathrm{H}(\mathrm{HO}) \mathrm{P} \cdot$ preferentially adopts the same $s$-trans conformation.

Charge densities exhibit the expected changes on traversing the series of media. Of the bonds present in the two radicals, the most polar is the $\mathrm{P}=\mathrm{O}$ bond of $\mathrm{H}_{2} \mathrm{P}(=\mathrm{O}) \cdot$ The charge polarization across this bond increases from 1.941 charge units in the gas phase to 2.015 charge units in water. However, the spin polarization varies in the opposite manner: spin density on phosphorus is 0.04 units greater in water than in the gas phase. The effects observed for the $\mathrm{H}(\mathrm{HO}) \mathrm{P} \cdot$ radical are similar, but of a much smaller magnitude.

The RSE of the $\mathrm{H}_{2} \mathrm{P}(=\mathrm{O}) \cdot$ radical is greatest in the gas phase, at $79.8 \mathrm{~kJ} \mathrm{~mol}^{-1}$, and decreases to $78.3 \mathrm{~kJ} \mathrm{~mol}^{-1}$ in water. Conversely, the RSE of the $\mathrm{H}(\mathrm{HO}) \mathrm{P} \cdot$ is highest in the two most polar media. Nevertheless, these effects are slight. To a good approximation, gas-phase calculations provide a reliable measure of the radicals' structural and energetic features.

Effect of Bonding Mode on the Stabilities of Phosphorus Radicals. To gain an initial indication of how the intrinsic stabilities of phosphonyl radicals compare with those of other classes of phosphorus-based radicals, we have calculated the RSEs of a range of radicals representing common phosphorus bonding modes. These are shown in Figure 1. In addition to the phosphonyl radical $\mathrm{PH}_{2}(=\mathrm{O}) \cdot$, we have considered the phosphinyl radical $\mathrm{PH}_{2} \cdot$, its protonated derivative $\mathrm{PH}_{3}{ }^{+}$, its $\mathrm{BH}_{3}$ and $\mathrm{AlCl}_{3}$ adducts, the amide and sulfide derivatives $\mathrm{PH}_{2}(=\mathrm{NH}) \cdot$ and $\mathrm{PH}_{2}(=\mathrm{S}) \cdot$, and the phosphoranyl radical $\mathrm{PH}_{4}{ }^{\circ}$. The RSEs for these species are given in Table 4. Also listed in the table are the calculated natural charges and spin densities on phosphorus, as calculated at the B3LYP/6-311+ G(3df,2p)//B3LYP/6-31+G(d) level.

Most of the species listed in Table 4 may be regarded as derivatives of the phosphinyl radical $\mathrm{H}_{2} \mathrm{P} \cdot$. The $\mathrm{RSE}$ of $\mathrm{H}_{2} \mathrm{P} \cdot$ is calculated to be $95.4 \mathrm{~kJ} \mathrm{~mol}^{-1}$, indicating that it possesses a much higher intrinsic stability, relative to its closed-shell parent species, than the methyl radical possesses relative to methane. Experimental measurements of BDEs have previously demonstrated this. ${ }^{39,40}$

The $\mathrm{H}_{2} \mathrm{P} \cdot$ radical is a $\pi$-type radical. Its unpaired electron resides in an orbital that is primarily phosphorus $3 \mathrm{p}$ in character, perpendicular to the $\mathrm{H}-\mathrm{P}-\mathrm{H}$ framework, while the phosphorus lone pair lies in the plane of the radical. Protonation at phosphorus decreases the radical's stability by some $78 \mathrm{~kJ}$ $\mathrm{mol}^{-1}$, consistent with the greater positive charge at the radical center and the greater phosphorus s character in the singly occupied molecular orbital (SOMO). The natural charge on phosphorus is +0.75 in the $\mathrm{H}_{3} \mathrm{P}^{+}{ }^{+}$radical, compared with only +0.11 in the unprotonated radical. The complexes of the $\mathrm{H}_{2} \mathrm{P}$. radical with the Lewis acids $\mathrm{AlCl}_{3}$ and $\mathrm{BH}_{3}$ are also destabilized for similar reasons, although to a smaller degree. In this connection, it is noteworthy that the phosphinyl radical displays similar features to those of aminyl radicals $\left(\mathrm{R}_{2} \mathrm{~N} \cdot\right)$. The latter are found to be rather unreactive in the unprotonated state, but their reactivity markedly increases upon protonation or coordination to a metal center. ${ }^{42}$

On going from the phosphinyl radical $\mathrm{H}_{2} \mathrm{P} \cdot$ to the phosphonyl radical $\mathrm{H}_{2} \mathrm{P}(=\mathrm{O}) \cdot$, there is a net destabilization of $15 \mathrm{~kJ} \mathrm{~mol}^{-1}$. This again reflects a withdrawal of electron density away from phosphorus (the calculated natural charge on phosphorus in $\mathrm{H}_{2} \mathrm{P}(=\mathrm{O}) \cdot$ is +1.04$)$ and an increase in the s character of the SOMO. It is somewhat surprising, therefore, that the sulfide and amide analogues $\mathrm{H}_{2} \mathrm{P}(=\mathrm{S}) \cdot$ and $\mathrm{H}_{2} \mathrm{P}(=\mathrm{NH}) \cdot$ should enjoy a marked increase in stabilization relative to the $\mathrm{H}_{2} \mathrm{P} \cdot$ radical. Their RSEs are, respectively, 27 and $34 \mathrm{~kJ} \mathrm{~mol}^{-1}$ greater than that of $\mathrm{H}_{2} \mathrm{P} \cdot$.

The calculated charges and $\alpha$ spin densities on the heteroatoms in these radicals are shown in Table 5. In all three radicals $\mathrm{H}_{2} \mathrm{P}(=\mathrm{X}) \cdot$, unlike in the protonated or Lewis acid adduct radicals, there is the capacity for electron delocalization as shown in Scheme 3. From the data in Table 5, it is evident that the radicals' stabilities depend on two factors. First, the electronegativity of $\mathrm{X}$ is a destabilizing influence, increasing (along with charge on phosphorus) in the order $\mathrm{S}<\mathrm{NH}<\mathrm{O}$. Second, there is the stabilizing influence of spin delocalization, which increases in the order $\mathrm{O}<\mathrm{S}<\mathrm{NH}$. That the radical $\mathrm{H}_{2} \mathrm{P}(=\mathrm{NH}) \cdot$ displays the greatest spin delocalization indicates the latter effect to be the dominant influence on stability. One may note that, according to the $\alpha$ spin densities, the radicals $\mathrm{H}_{2} \mathrm{P}(=\mathrm{NH}) \cdot$ and $\mathrm{H}_{2} \mathrm{P}(=\mathrm{S}) \cdot$ would better be described as nitrogen-based and sulfur-based radicals, respectively, rather than as phosphorus-based radicals. The phosphonyl radical $\mathrm{H}_{2} \mathrm{P}(=\mathrm{O}) \cdot$ has greater phosphorus radical character.

The phosphoranyl radical $\mathrm{H}_{4} \mathrm{P} \cdot$ has a much greater RSE than the phosphinyl radical $\mathrm{H}_{2} \mathrm{P} \cdot$. We have previously drawn attention to the dangers of using hydrogen transfer as the type of reaction used to measure radical stability in phosphoranyl radicals $^{2 j}$ and therefore cannot say with certainty that the phosphoranyl radical is inherently more stable than the phosphinyl radical. However, the RSEs do imply that the fivecoordinate phosphorane $\mathrm{PH}_{5}$ is a better hydrogen donor than the three-coordinate phosphine $\mathrm{PH}_{3}$. 
TABLE 4: Radical Stabilization Energies of Phosphorus Radicals Having Different Phosphorus Bonding Modes ${ }^{a}$

\begin{tabular}{|c|c|c|c|c|c|}
\hline Number & Structure & $\begin{array}{c}\text { Electronic } \\
\text { state }\end{array}$ & $\begin{array}{c}\text { RSE } \\
\left(\mathrm{kJ} \mathrm{mol}^{-1}\right)\end{array}$ & $\begin{array}{c}\text { Charge on } \\
\mathbf{P}\end{array}$ & $\begin{array}{c}\alpha \text { Spin } \\
\text { Density on } \\
\mathbf{P}\end{array}$ \\
\hline 1 & & ${ }^{2} \mathrm{~A}^{\prime}$ & 80.6 & 1.043 & 0.512 \\
\hline 2 & & ${ }^{2} \mathrm{~B}_{1}$ & 95.4 & 0.113 & 1.036 \\
\hline 3 & & ${ }^{2} \mathrm{~A}_{1}$ & 17.4 & 0.747 & 0.995 \\
\hline 4 & & ${ }^{2} \mathrm{~A}^{\prime}$ & 66.7 & 0.516 & 0.764 \\
\hline 5 & & ${ }^{2} \mathrm{~A}^{\prime}$ & 64.3 & 0.242 & 0.925 \\
\hline 6 & $\mathrm{NH}$ & ${ }^{2} \mathrm{~A}$ & 129.8 & 0.649 & 0.235 \\
\hline 7 & S & ${ }^{2} \mathrm{~A}^{\prime}$ & 122.2 & 0.295 & 0.275 \\
\hline 8 & $\mathrm{H}$ & ${ }^{2} \mathrm{~A}_{1}$ & 206.7 & 0.134 & 0.346 \\
\hline
\end{tabular}

${ }^{a}$ RSEs were calculated at the G3(MP2)-RAD(+) level of theory and include scaled zero-point energy corrections. Natural charges and $\alpha$ spin densities were calculated at the B3LYP/6-311+G(3df,2p)//B3LYP/6-31+G(d) level of theory.

TABLE 5: Natural Charges and $\alpha$ Spin Densities on the Heteroatoms in the Radicals $\mathbf{H}_{2} \mathbf{P}(=\mathbf{O}) \cdot \mathbf{H}_{2} \mathbf{P}(=\mathbf{N H}) \cdot$, and $\mathrm{H}_{2} \mathbf{P}(=S)^{\bullet a}$

\begin{tabular}{|c|c|c|c|c|c|c|c|c|}
\hline & 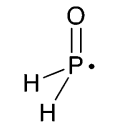 & & & $\underset{\mathrm{H}}{\|_{\mathrm{H}}^{\mathrm{NH}}}$ & & & $\begin{array}{l}\prod_{\mathrm{H}}^{\mathrm{S}} \\
\mathrm{H} \\
\mathrm{H}\end{array}$ & \\
\hline Atom & Charge & $\begin{array}{l}\alpha \text { Spin } \\
\text { Density }\end{array}$ & Atom & Charge & $\begin{array}{c}\alpha \text { Spin } \\
\text { Density }\end{array}$ & Atom & Charge & $\begin{array}{l}\alpha \text { Spin } \\
\text { Density }\end{array}$ \\
\hline $\mathrm{P}$ & +1.043 & 0.512 & $P$ & +0.649 & 0.235 & $P$ & +0.295 & 0.275 \\
\hline $\mathrm{O}$ & -0.898 & 0.389 & $\mathrm{~N}$ & -0.913 & 0.695 & S & -0.275 & 0.663 \\
\hline
\end{tabular}

${ }^{a}$ Calculated at the B3LYP/6-311+G(3df,2p)//B3LYP/6-31+G(d) level of theory.

SCHEME 3

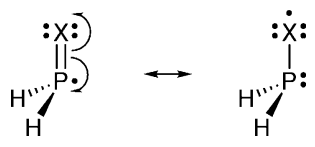

Effects of Substituents on the Stabilities of Phosphonyl Radicals XYP $(=\mathbf{O}) \cdot$. In order to examine substituent effects in phosphonyl radicals, we have examined a range of radicals of the type $\mathrm{XYP}(=\mathrm{O}) \cdot$. The radicals' structures are shown in Figure 2, and their calculated RSEs are given in Table 6. Also listed in Table 6 are the calculated $\alpha$ spin densities and charges on phosphorus in the radicals, as well as the charges on phosphorus in the corresponding closed-shell hydrides $\mathrm{HXYP}(=\mathrm{O})$.

Of initial note is the small impact of $\pi$-withdrawal. For example, the phenyl group provides an additional stabilization of only $3.1 \mathrm{~kJ} \mathrm{~mol}^{-1}$ compared with $\mathrm{X}=\mathrm{H}$. In comparison, the RSE of the benzyl radical (relative to methyl) at the same level of theory is $58.9 \mathrm{~kJ} \mathrm{~mol}^{-1}$. For one thing, it is true that third-row elements have in general a reduced tendency to engage in $\pi$-bonding compared with their lighter congeners. In phosphonyl radicals, however, another important factor hampering $\pi$-withdrawal is the radicals' geometries. The benzyl radical 


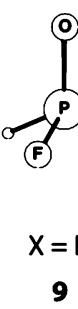

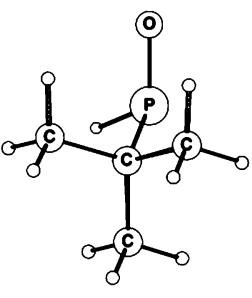
$\mathrm{X}=\mathrm{IBu}$ 13

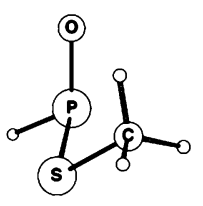

$\mathrm{X}=$ MeS

17

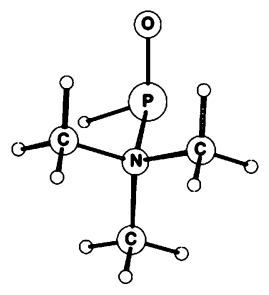

$\mathrm{X}=\mathrm{Me}_{3} \mathrm{~N}^{+}$

10

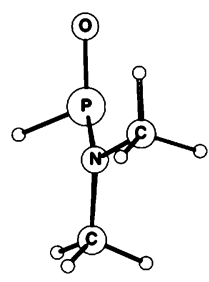

$X=\mathrm{Me}_{2} \mathrm{~N}$

14

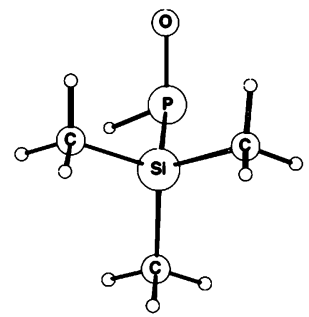

$\mathrm{X}=\mathrm{Me}_{3} \mathrm{Si}$

18

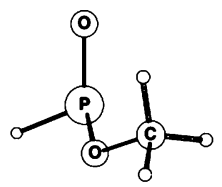

$\mathrm{X}=\mathrm{MeO}$

11

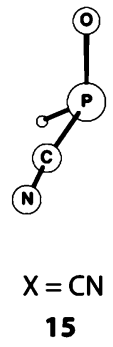

15

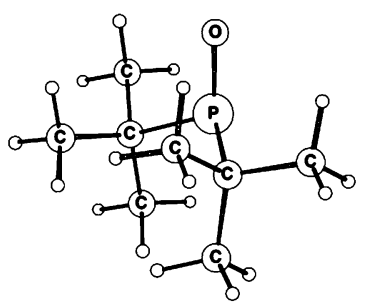

$t_{\mathrm{Bu}_{2} \mathrm{P}(=\mathrm{O}) \cdot}$

19

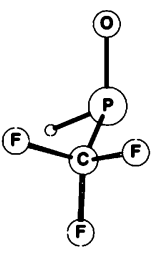

$\mathrm{X}=\mathrm{CF}_{3}$

12

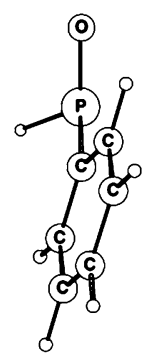

$\mathrm{X}=\mathrm{Ph}$

16
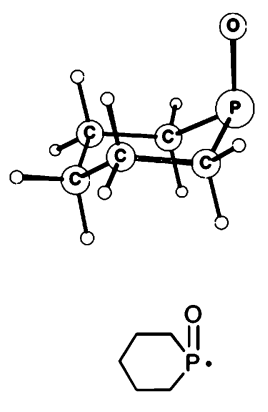

Figure 2. Optimized geometries of phosphonyl radicals $\mathrm{XHP}(=\mathrm{O}) \cdot($ various $\mathrm{X}$ ), and of two dialkylphosphonyl radicals (obtained at the B3LYP/ 6-31+G(d) level).

has a planar geometry which enables maximal overlap between the $2 \mathrm{p}$ orbital on the radical carbon and the $\pi^{*}$ orbitals of the phenyl ring. ${ }^{20,43}$ In contrast, the phosphonyl radicals listed in Table 6 are pyramidal at phosphorus. For example, the average of the three angles at phosphorus in the radical $\mathrm{H}(\mathrm{Ph}) \mathrm{P}(=\mathrm{O})$. is $110.9^{\circ}$. Although the dihedral angle between the phenyl ring and the phosphorus component of the SOMO is approximately $90^{\circ}$, the pyramidal geometry enforces a reduction in overlap between the SOMO and the phenyl $\pi^{*}$ orbitals. The total spin density on the $\mathrm{Ph}$ group in the radical $\mathrm{H}(\mathrm{Ph}) \mathrm{P}(=\mathrm{O}) \cdot$ is only $11 \%$. As a result, the stabilizing effect of the phenyl group is low. Likewise, the $\mathrm{CN}$ group is unable to provide significant $\pi$-stabilization in the $\mathrm{H}(\mathrm{NC}) \mathrm{P}(=\mathrm{O}) \cdot$ radical (accepting only $8 \%$ of the total spin density); indeed, competing $\sigma$-withdrawal results in a destabilization of $0.5 \mathrm{~kJ} \mathrm{~mol}^{-1}$.

The influence of steric effects is demonstrated by the two ${ }^{t} \mathrm{Bu}$-substituted radicals. The monosubstituted radical $\mathrm{H}\left({ }^{t} \mathrm{Bu}\right) \mathrm{P}(=\mathrm{O}) \cdot$ enjoys greater stabilization (RSE $75.7 \mathrm{~kJ} \mathrm{~mol}^{-1}$ ) than the radical ${ }^{t} \mathrm{Bu}\left({ }^{t} \mathrm{Bu}\right) \mathrm{P}(=\mathrm{O}) \cdot\left(\mathrm{RSE} 71.8 \mathrm{~kJ} \mathrm{~mol}^{-1}\right)$. Although the $\mathrm{H}\left({ }^{t} \mathrm{Bu}\right) \mathrm{P}(=\mathrm{O}) \cdot$ radical is more crowded at phosphorus (sum of bond angles $109.8^{\circ}$ compared with $112.1^{\circ}$ ), the unfavorable nonbonded (e.g., $\mathrm{H} \cdots \mathrm{H})$ interactions between the ${ }^{t} \mathrm{Bu}$ groups in the disubstituted radical ${ }^{t} \mathrm{Bu}\left({ }^{t} \mathrm{Bu}\right) \mathrm{P}(=\mathrm{O}) \cdot$ lead to a lower RSE.

Having already considered the inefficiency of $\pi$-withdrawal as a mode of stabilization, it is noteworthy that $\pi$-donation also provides little stabilization. This is surprising, because in alkyl radicals pyramidalization of the radical center favors stabilization by lone-pair donors. ${ }^{20,43} \mathrm{NBO}$ analysis indicates that the $\pi$-donor effects are quite large; for example, donation from the $\mathrm{OMe}$ lone pair into the antibonding $\mathrm{P}=\mathrm{O}$ orbital of the $\mathrm{H}(\mathrm{MeO}) \mathrm{P}(=\mathrm{O})$ • radical is worth $54 \mathrm{~kJ} \mathrm{~mol}^{-1}$, while the corresponding interaction involving the $\mathrm{NMe}_{2}$ lone pair in the $\mathrm{H}\left(\mathrm{Me}_{2} \mathrm{~N}\right) \mathrm{P}(=\mathrm{O}) \cdot$ radical is worth $44 \mathrm{~kJ} \mathrm{~mol}^{-1}$. However, we believe that the lack of evidence for $\pi$-donation as a stabilizing mechanism in phosphonyl radicals stems from the high positive charge at phosphorus: the substituents that are potentially the best lone-pair donors are also those with the greatest $\sigma$-withdrawing effects.

There is a negative correlation $\left(R^{2}=0.71\right)$ between phosphonyl radical stability and the positive charge on phosphorus. The importance of this influence on radical stability stems from the highly polar nature of the $\mathrm{P}=\mathrm{O}$ bond. These radicals are well described as zwiterionic: $\mathrm{XYP}^{+}-\mathrm{O}^{-}$. For example, in the $\mathrm{H}_{2} \mathrm{P}(=\mathrm{O}) \cdot$ radical, the calculated charge on phosphorus is +1.04 . Further withdrawal of electron density from the already electrondeficient phosphorus center is inherently destabilizing. Conversely, the $\mathrm{SiMe}_{3}$ substituent, which is electron-releasing ( $\mathrm{Si}$ less electronegative than $\mathrm{P}$ ), is the only group found to exert significant stabilization.

This strong inverse relationship between stability and charge on phosphorus speaks for the critical importance of $\sigma$-effects in these highly polar radicals. Spin delocalization, by contrast, is only a minor concern. The delocalization of $\alpha$ spin density onto the group $\mathrm{X}$ never exceeds a value of $21 \%$ : this upper 
TABLE 6: Radical Stabilization Energies of the Phosphonyl Radicals XYO $(=0)$; , Together with the Natural Charges and $\alpha$ Spin Densities on Phosphorus in the Radicals and Natural Charges on Phosphorus in the Closed-Shell Hydrides HXYP $(=0)^{a}$

\begin{tabular}{|c|c|c|c|c|c|c|}
\hline Number & $\mathbf{X}, \mathbf{Y}$ & $\begin{array}{l}\text { Electronic } \\
\text { state }\end{array}$ & $\begin{array}{c}\text { RSE } \\
(\mathbf{k J} \\
\left.\mathrm{mol}^{-1}\right)\end{array}$ & $\begin{array}{c}\text { Charge on } \\
\text { P in } \\
\text { XYP(=O)• }\end{array}$ & $\begin{array}{c}\alpha \text { Spin } \\
\text { Density } \\
\text { on P in } \\
\text { XYP }=0 \text { ( }) \bullet\end{array}$ & $\begin{array}{c}\text { Charge on } \\
\text { P in } \\
\text { HXYP(=O) }\end{array}$ \\
\hline 1 & $\mathrm{H}, \mathrm{H}$ & ${ }^{2} A^{\prime}$ & 80.6 & 1.043 & 0.512 & 1.309 \\
\hline 9 & $\mathrm{~F}, \mathrm{H}$ & ${ }^{2} \mathrm{~A}$ & 64.1 & 1.565 & 0.515 & 1.807 \\
\hline 10 & $\begin{array}{l}\mathrm{Me}_{3} \mathrm{~N}^{+} \\
\mathrm{H}\end{array}$ & ${ }^{2} \mathrm{~A}$ & 65.6 & 1.434 & 0.445 & 1.651 \\
\hline 11 & $\mathrm{MeO}, \mathrm{H}$ & ${ }^{2} \mathrm{~A}$ & 70.3 & 1.526 & 0.530 & 1.774 \\
\hline 12 & $\mathrm{CF}_{3}, \mathrm{H}$ & ${ }^{2} \mathrm{~A}$ & 74.1 & 1.181 & 0.479 & 1.421 \\
\hline 13 & ${ }^{t} \mathrm{Bu}, \mathrm{H}$ & ${ }^{2} \mathrm{~A}$ & 75.7 & 1.303 & 0.536 & 1.549 \\
\hline 14 & $\mathrm{Me}_{2} \mathrm{~N}, \mathrm{H}$ & ${ }^{2} \mathrm{~A}$ & 79.1 & 1.434 & 0.477 & 1.679 \\
\hline 15 & $\mathrm{NC}, \mathrm{H}$ & ${ }^{2} \mathrm{~A}$ & 80.1 & 1.260 & 0.475 & 1.469 \\
\hline 16 & $\mathrm{Ph}, \mathrm{H}$ & ${ }^{2} \mathrm{~A}$ & 83.7 & 1.324 & 0.529 & 1.542 \\
\hline 17 & $\mathrm{MeS}, \mathrm{H}$ & ${ }^{2} \mathrm{~A}$ & 90.7 & 1.114 & 0.481 & 1.334 \\
\hline 18 & $\mathrm{Me}_{3} \mathrm{Si}, \mathrm{H}$ & ${ }^{2} \mathrm{~A}$ & 102.2 & 0.856 & 0.521 & 1.097 \\
\hline 19 & ${ }^{t} \mathrm{Bu},{ }^{t} \mathrm{Bu}$ & ${ }^{2} \mathrm{~A}$ & 71.8 & 1.549 & 0.549 & 1.778 \\
\hline 20 & \II & ${ }^{2} \mathrm{~A}^{\prime}$ & 70.3 & 1.491 & 0.551 & 1.738 \\
\hline
\end{tabular}

${ }^{a}$ RSEs were calculated at the G3(MP2)-RAD(+) level of theory and include scaled zero-point energy corrections. Natural charges and $\alpha$ spin densities were calculated at the B3LYP/6-311+G(3df,2p)//B3LYP/6-31+G(d) level of theory.

value is found for $\mathrm{X}=\mathrm{NMe}_{2}$, while $\mathrm{X}=\mathrm{SMe}$ is the next highest $(17 \%)$.

We also find a strong positive correlation $\left(R^{2}=0.99\right)$ between the charge on phosphorus in the phosphonyl radicals and that in their corresponding closed-shell hydrides. This suggests that the substituent effects in the radicals mirror those in the parent hydrides, and as a result, our choice of using hydrogen-transfer reactions as the means to measure phosphonyl radicals' stability appears to be a valid one. A different situation was previously observed in our study of the phosphoranyl radicals $\mathrm{X}\left(\mathrm{CH}_{3}\right)_{3} \mathrm{P} \cdot$ : we argued in that case that the standard hydrogen-transfer reaction was inadequate as a measure of phosphoranyl radical stability and a better measure was a $\mathrm{P}-\mathrm{CH}_{3}$ dissociation reaction. ${ }^{2 \mathrm{j}}$

It is worthwhile to compare the substituent effects in phosphonyl radicals with those previously determined for phosphoranyl radicals. In our previous study ${ }^{2 j}$ of the phosphoranyl radicals $\mathrm{X}\left(\mathrm{CH}_{3}\right)_{3} \mathrm{P} \cdot$, which adopt a structure based on a trigonal bipyramid at phosphorus (with the unpaired electron occupying the vacant equatorial position), we noted that the SOMO has components that could be described as the $\sigma$-antibonding orbitals of the axial $\mathrm{P}-\mathrm{X}$ or $\mathrm{P}-\mathrm{CH}_{3}$ bonds. Substituents $\mathrm{X}$ that were either $\sigma$-withdrawing or $\pi$-donating provided stabilization to these phosphoranyl radicals. Phosphonyl radicals, like phosphoranyl radicals, also possess some $\sigma$-character. However, their resistance to withdrawal of electron density from the positively charged radical center through either the $\sigma$ - or the $\pi$-framework means that a different set of substituent effects are observed: notably, $\sigma$-withdrawing substituents are destabilizing.
Effects of Substituents on the Stabilities of Hydroxyphosphinyl Radicals $\mathbf{X}(\mathbf{O H}) \mathbf{P} \cdot$. We turn now to investigating the possibility of a tautomeric equilibrium involving phosphonyl radicals $\mathrm{XHP}(=\mathrm{O}) \cdot$ and hydroxyphosphinyl radicals $\mathrm{X}(\mathrm{HO}) \mathrm{P} \cdot$. The geometries of hydroxyphosphinyl radicals bearing a range of $X$ substituents are shown in Figure 3. In Table 7 are listed their RSEs, along with the natural charges and $\alpha$ spin densities on phosphorus.

The ordering of stabilities for the hydroxyphosphinyl radicals is different from that of their isomeric phosphonyl radicals. Electronegativity effects again play a significant role, but now substituents that can interact with the radical center through a $\pi$-mechanism exert a greater effect.

When $\mathrm{X}$ is a $\pi$-acceptor group such as $\mathrm{CN}$ or $\mathrm{Ph}$, the radicals assume a planar geometry, as appropriate for maximizing the delocalization of spin density into the X substituent's $\pi^{*}$ orbitals. The total spin density borne by these two $\mathrm{X}$ groups in their respective hydroxyphosphinyl radicals are accordingly somewhat greater than in the corresponding phosphonyl radicals: the $\mathrm{CN}$ group in the $(\mathrm{NC})(\mathrm{HO}) \mathrm{P} \cdot$ radical bears $13 \%$ of the total spin density [compared with $8 \%$ in the radical $\mathrm{H}(\mathrm{NC}) \mathrm{P}(=\mathrm{O}) \cdot$ ], while the $\mathrm{Ph}$ group in the $(\mathrm{Ph})(\mathrm{HO}) \mathrm{P} \cdot$ radical bears $16 \%$ of the total spin density [compared with $11 \%$ in the radical $\mathrm{H}(\mathrm{Ph}) \mathrm{P}(=\mathrm{O}) \cdot$ ].

To assess whether two substituents on phosphorus can interact, we have examined the specific case of (NC)(HO)P. The RSE of this radical is $123.9 \mathrm{~kJ} \mathrm{~mol}^{-1}$. By contrast, the RSE of the radical $\mathrm{H}(\mathrm{NC}) \mathrm{P} \cdot$ is $108.1 \mathrm{~kJ} \mathrm{~mol}^{-1}$, while that of the $\mathrm{H}(\mathrm{HO}) \mathrm{P}$. radical is $115.0 \mathrm{~kJ} \mathrm{~mol}^{-1}$. When these latter values are compared with the RSE of the radical $\mathrm{H}_{2} \mathrm{P} \cdot\left(95.4 \mathrm{~kJ} \mathrm{~mol}^{-1}\right)$, it is seen that the combined effect of the hydroxy and cyano 

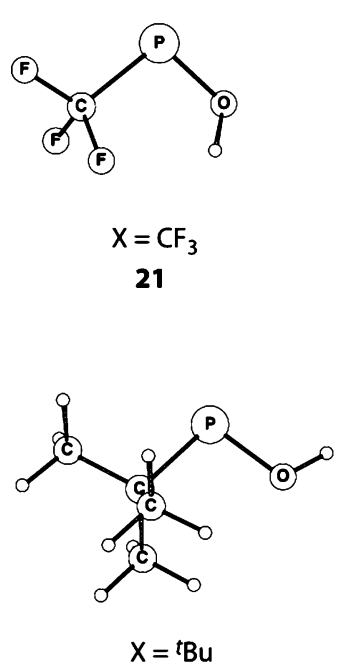

25

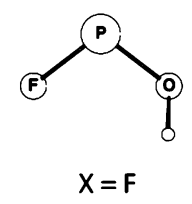

29

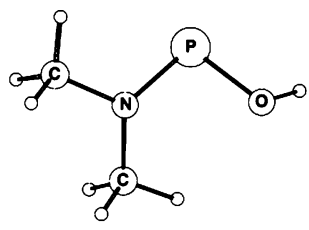

$\mathrm{X}=\mathrm{Me}_{2} \mathrm{~N}$

22
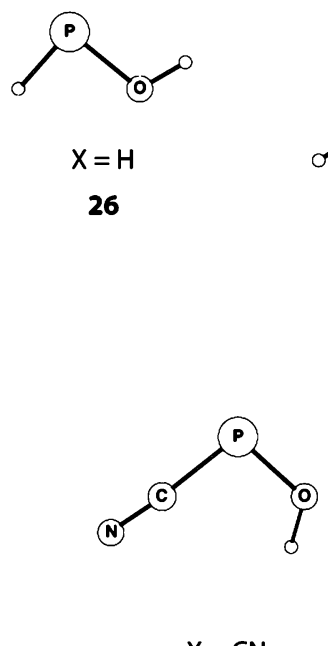

$X=C N$
30

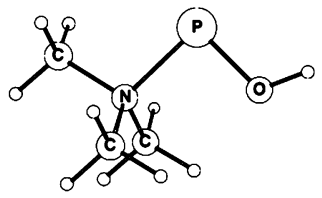

$\mathrm{X}=\mathrm{Me}_{3} \mathrm{~N}^{+}$

23

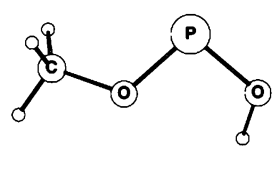

$\mathrm{X}=\mathrm{MeO}$

24

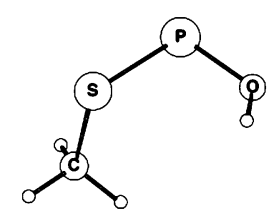

$\mathrm{X}=\mathrm{MeS}$

27

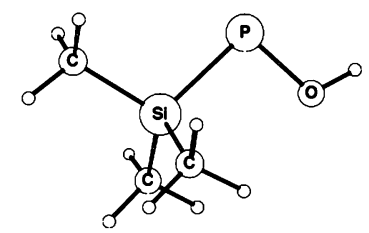

$\mathrm{X}=\mathrm{Me}_{3} \mathrm{Si}$

28

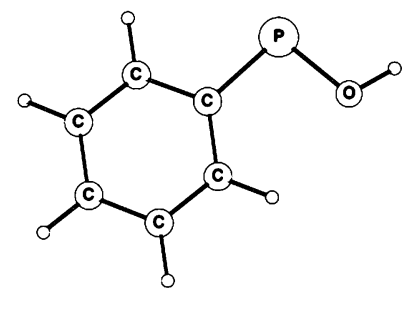

$\mathrm{X}=\mathrm{Ph}$

Figure 3. Optimized geometries of hydroxyphosphinyl radicals $\mathrm{X}(\mathrm{OH}) \mathrm{P} \cdot$ (obtained at the B3LYP/6-31+G(d) level).

TABLE 7: Radical Stabilization Energies of the Hydroxyphosphinyl Radicals X(HO)P., Together with the Natural Charges and $\alpha$ Spin Densities on Phosphorus in the Radicals and Natural Charges on Phosphorus in the Closed-Shell Hydrides X(HO)PH ${ }^{a}$

\begin{tabular}{llccccc}
\hline no. & \multicolumn{1}{c}{$\mathrm{X}$} & $\begin{array}{c}\text { electronic } \\
\text { state }\end{array}$ & $\begin{array}{c}\text { RSE } \\
\left(\mathrm{kJ} \mathrm{mol}^{-1}\right)\end{array}$ & $\begin{array}{c}\text { charge on } \mathrm{P} \\
\text { in X(HO)P. }\end{array}$ & $\begin{array}{c}\alpha \text { spin } \\
\text { densityon } \mathrm{P}\end{array}$ & $\begin{array}{c}\text { charge on } \mathrm{P} \\
\text { in X(HO)PH }\end{array}$ \\
\hline $\mathbf{2 1}$ & $\mathrm{CF}_{3}$ & ${ }^{2} \mathrm{~A}$ & 107.0 & 0.818 & 0.863 & 0.862 \\
$\mathbf{2 2}$ & $\mathrm{Me}_{2} \mathrm{~N}$ & ${ }^{2} \mathrm{~A}$ & 109.3 & 0.893 & 0.793 & 1.026 \\
$\mathbf{2 3}$ & $\mathrm{Me}_{3} \mathrm{~N}^{+}$ & ${ }^{2} \mathrm{~A}^{\prime \prime}$ & 109.6 & 1.080 & 0.884 & 1.125 \\
$\mathbf{2 4}$ & $\mathrm{MeO}$ & ${ }^{2} \mathrm{~A}$ & 110.6 & 1.030 & 0.850 & 1.135 \\
$\mathbf{2 5}$ & ${ }^{t} \mathrm{Bu}$ & ${ }^{2} \mathrm{~A}^{\prime \prime}$ & 113.3 & 0.814 & 0.898 & 0.876 \\
$\mathbf{2 6}$ & $\mathrm{H}$ & ${ }^{2} \mathrm{~A}^{\prime \prime}$ & 115.0 & 0.565 & 0.912 & 0.624 \\
$\mathbf{2 7}$ & $\mathrm{MeS}$ & ${ }^{2} \mathrm{~A}$ & 115.5 & 0.704 & 0.855 & 0.754 \\
$\mathbf{2 8} \mathrm{Me} \mathrm{Si}_{3}$ & ${ }^{2} \mathrm{~A}^{\prime \prime}$ & 117.5 & 0.410 & 0.867 & 0.426 \\
$\mathbf{2 9}$ & $\mathrm{F}$ & ${ }^{2} \mathrm{~A}$ & 118.4 & 1.106 & 0.898 & 1.225 \\
$\mathbf{3 0}$ & $\mathrm{NC}$ & ${ }^{2} \mathrm{~A}^{\prime \prime}$ & 123.9 & 0.914 & 0.769 & 0.925 \\
$\mathbf{3 1} \mathrm{Ph}$ & ${ }^{2} \mathrm{~A}^{\prime \prime}$ & 133.0 & 0.851 & 0.767 & 0.875
\end{tabular}

${ }^{a}$ RSEs were calculated at the G3(MP2)-RAD(+) level of theory and include scaled zero-point energy corrections. Natural charges and $\alpha$ spin densities were calculated at the B3LYP/6-311+G(3df,2p)//B3LYP/ $6-31+G(d)$ level of theory.

substituents together does not exceed the sum of their individual stabilization effects. Thus, the radical (NC)(HO)P is not an example of a captodatively stabilized radical. Nevertheless, the presence of the two stabilizing groups $\mathrm{CN}$ and $\mathrm{OH}$ makes the (NC)(HO)P radical one of the most stabilized of the hydroxyphosphinyl radicals listed in Table 7.

The range of substituent effects in the hydroxyphosphinyl radicals is quite small. The RSEs span a range of only $26 \mathrm{~kJ}$ mol $^{-1}$, compared with $38 \mathrm{~kJ} \mathrm{~mol}^{-1}$ for the phosphonyl radicals. This appears due in part to the stabilizing effect of the $\mathrm{OH}$ group on phosphorus. By replacing one of the hydrogens of the $\mathrm{H}_{2} \mathrm{P}$ radical with hydroxy group to give the $\mathrm{H}(\mathrm{HO}) \mathrm{P} \cdot$ radical, the
RSE increases substantially, from 95.4 to $115.0 \mathrm{~kJ} \mathrm{~mol}^{-1}$. Thereafter, the effects of replacing the second hydrogen with another substituent $\mathrm{X}$ are minor.

The $\sigma$ - and $\pi$-characteristics of both the X substituent and the $\mathrm{OH}$ group must be considered together in the hydroxyphosphinyl radicals. For example, unlike the $\pi$-acceptor groups $\mathrm{CN}$ and $\mathrm{Ph}$, the pseudo- $\pi$-acceptor groups $\mathrm{CF}_{3}$ and $\mathrm{NMe}_{3}{ }^{+}$are found to destabilize the hydroxyphosphinyl radicals. Here, destabilization by $\sigma$-withdrawal appears to negate the modest pseudo- $\pi$ acceptor stabilization. By contrast, the ${ }^{t} \mathrm{Bu}$ group, which provides some capacity for pseudo- $\pi$-acceptance but has less $\sigma$-withdrawing character, is less destabilizing.

A notable observation may be made for the radical $\left(\mathrm{Me}_{3} \mathrm{Si}\right)(\mathrm{HO}) \mathrm{P} \cdot$. Here the $\sigma$-donor $/ \pi$-acceptor properties of the silyl group provide a modest $2.5 \mathrm{~kJ} \mathrm{~mol}^{-1}$ of stabilization relative to the radical $\mathrm{H}(\mathrm{HO}) \mathrm{P} \cdot$. This unremarkable stabilization is clearly different from that found for the $\mathrm{Me}_{3} \mathrm{Si}$-substituted phosphonyl radical, which reinforces the important role played by electronegativity effects in the stabilities of phosphonyl radicals.

For the subset of $\pi$-donor substituents $\mathrm{NMe}_{2}, \mathrm{OMe}, \mathrm{SMe}$, and F, the calculated stability trends are not straightforward. It has previously been shown for carbon-centered radicals that when a radical center interacts with one $\pi$-donor substituent, the mixing of the SOMO and the substituent's $\pi$-orbital lowers the energy of the $\pi$-orbital while raising the energy of the SOMO. ${ }^{20,43}$ This is stabilizing, but because the unpaired electron now lies at higher energy, it has less capacity to interact with a second $\pi$-donor substituent. Therefore, in the hydroxyphosphinyl radicals, which all bear a $\pi$-donor $\mathrm{OH}$ group, one would expect to see significant further stabilization only if $\mathrm{X}$ is a stronger $\pi$-donor than $\mathrm{OH}$. 
For $\mathrm{X}=\mathrm{SMe}$, there is a very small stabilization and for $\mathrm{X}$ $=\mathrm{NMe}_{2}$ or OMe there is a net destabilization. This does not fit well with the order normally assumed for the groups' $\pi$-donor abilities. Here, the radicals' geometries provide some clues. When $\mathrm{X}=\mathrm{OMe}$, the radical $\mathrm{X}(\mathrm{HO}) \mathrm{P} \cdot$ takes an approximately planar structure, in which the dihedral angles $\mathrm{C}-\mathrm{O}-\mathrm{P}-\mathrm{O}$ and $\mathrm{H}-\mathrm{O}-\mathrm{P}-\mathrm{O}$ are $-175.6^{\circ}$ and $12.5^{\circ}$, respectively. When $\mathrm{X}=$ $\mathrm{NMe}_{2}$, there is slightly more deviation from planarity (the dihedral angles $\mathrm{C}-\mathrm{N}-\mathrm{P}-\mathrm{O}$ and $\mathrm{H}-\mathrm{O}-\mathrm{P}-\mathrm{N}$ being $159.4^{\circ}$ and $152.6^{\circ}$, respectively). For $\mathrm{X}=\mathrm{SMe}$, the radical is distinctly nonplanar. Here, the $\mathrm{OH}$ group lies roughly in the same plane as the $\mathrm{O}-\mathrm{P}-\mathrm{S}$ unit (dihedral $\mathrm{H}-\mathrm{O}-\mathrm{P}-\mathrm{S}-16.9^{\circ}$ ), but the $\mathrm{SMe}$ group is tilted out of the $\mathrm{O}-\mathrm{P}-\mathrm{S}$ plane to an angle of $-79.3^{\circ}$. Considering that efficient overlap between the singly occupied orbital and the lone pair on $\mathrm{X}$ involves a planar $\mathrm{P}-\mathrm{X}$ unit, it follows that $\pi$-donation from the $\mathrm{X}$ lone pair into the singly occupied orbital varies in the order $\mathrm{OMe}>\mathrm{NMe}_{2}>\mathrm{SMe}$.

These geometries are suggestive of homoanomeric interactions, which can occur when multiple lone-pair donor substituents are bound to a radical center. For example, we have previously noted ${ }^{21}$ that in carbon-centered radicals of the type $\left(\mathrm{YCH}_{2} \mathrm{~S}\right)(\mathrm{MeS})(\mathrm{Me}) \mathrm{C} \cdot$, the presence of an electron-withdrawing group such as $\mathrm{CN}$ in the $\mathrm{Y}$ position led the two SR groups to assume different orientations. The SMe group lay in the plane of the radical center, acting as a $\pi$-donor, while the $\mathrm{SCH}_{2} \mathrm{CN}$ group lay with its $\mathrm{S}-\mathrm{C}$ bond roughly perpendicular to the plane, acting as a pseudo- $\pi$-acceptor. Other homoanomeric effects like these have been well documented. ${ }^{44}$

The operation of homoanomeric interactions in the hydroxyphosphinyl radicals is supported by NBO analysis. First, in the $(\mathrm{MeO})(\mathrm{HO}) \mathrm{P} \cdot$ radical, the donor-acceptor interactions involving the oxygen lone pairs and the SOMO are nearly equi-energetic, at 80 (OMe group) and $81 \mathrm{~kJ} \mathrm{~mol}^{-1}$ (OH group). By contrast, donation from the SOMO into the $\mathrm{O}-\mathrm{C}$ antibonding orbital is worth only $1 \mathrm{~kJ} \mathrm{~mol}^{-1}$. In the $\left(\mathrm{Me}_{2} \mathrm{~N}\right)(\mathrm{HO}) \mathrm{P}$. radical, the only significant lone-pair-SOMO is that involving the $\mathrm{OH}$ group, at $44 \mathrm{~kJ} \mathrm{~mol}^{-1}$, while donation from the SOMO into one of the $\mathrm{N}-\mathrm{C}$ antibonding orbitals is worth $12 \mathrm{~kJ} \mathrm{~mol}^{-1}$. Finally, the $(\mathrm{MeS})(\mathrm{HO}) \mathrm{P} \cdot$ radical displays an $\mathrm{O}$ (lone-pair)-P(SOMO) interaction of $6 \mathrm{~kJ} \mathrm{~mol}^{-1}$, compared with an interaction of $15 \mathrm{~kJ}$ $\mathrm{mol}^{-1}$ from the SOMO into the $\mathrm{S}-\mathrm{C}$ antibonding orbital. These figures support the notion that in hydroxyphosphinyl radicals (i) the $\mathrm{OMe}$ and $\mathrm{NMe}_{2}$ groups behave primarily as lone-pair donors (preferring a nearly planar $\mathrm{P}-\mathrm{X}$ unit), whereas (ii) the $\mathrm{SMe}$ group behaves as a pseudo- $\pi$-acceptor using its $\mathrm{S}-\mathrm{C} \sigma^{*}$ orbital (preferring a nonplanar $\mathrm{P}-\mathrm{X}$ unit). Because the extra stabilizing effect of a second lone-pair donor is reduced by the presence of the first, the change in RSEs on going from the parent hydroxyphosphinyl radical to the $\mathrm{OMe}-$ and $\mathrm{NMe}_{2}-$ substituted derivatives is minor and, in fact, is outweighed by these groups' $\sigma$-acceptor properties. On the other hand, for the $\mathrm{SMe}$ group, the electron delocalization into the $\mathrm{S}-\mathrm{C} \sigma^{*}$ orbital adds significant further stabilization to the lone-pair donation already coming from $\mathrm{OH}$.

The relative stability of the $\mathrm{F}(\mathrm{HO}) \mathrm{P}$ - is noteworthy. The origins of this stability are not obvious. We note, however, that in this radical, the two lone-pair-SOMO interactions are almost equi-energetic, at $50(\mathrm{~F})$ and $54 \mathrm{~kJ} \mathrm{~mol}^{-1}(\mathrm{OH})$. Nevertheless, the dihedral angle $\mathrm{H}-\mathrm{O}-\mathrm{P}-\mathrm{F}$ is $-50.3^{\circ}$, and there is an $8 \mathrm{~kJ}$ $\mathrm{mol}^{-1}$ interaction between the SOMO and the $\mathrm{O}-\mathrm{H}$ antibonding orbital. The possibility of stabilization through hydrogen bonding can also not be discounted: in contrast to the parent hydroxyphosphinyl radical, which adopts an $s$-trans conformation, the $\mathrm{F}(\mathrm{HO}) \mathrm{P} \cdot$ radical adopts an $s$-cis conformation with a $\mathrm{H} \cdots \mathrm{F}$
TABLE 8: Values of $\Delta H_{0}$ for the Reaction XHP $(=0) \cdot \rightarrow$ (HO)XP. $(\text { Various X })^{a}$

\begin{tabular}{lc}
\hline \multicolumn{1}{c}{$\mathrm{X}$} & $\Delta H_{0}\left(\mathrm{~kJ} \mathrm{~mol}^{-1}\right)$ \\
\hline $\mathrm{NMe}_{2}$ & -11.0 \\
$\mathrm{OMe}$ & -12.6 \\
${ }^{t} \mathrm{Bu}$ & -17.9 \\
$\mathrm{SiMe}$ & -19.2 \\
$\mathrm{~F}$ & -26.3 \\
$\mathrm{SMe}$ & -30.1 \\
$\mathrm{Ph}$ & -32.7 \\
$\mathrm{H}$ & -36.0 \\
$\mathrm{CF}$ & -45.9 \\
$\mathrm{NC}_{3}$ & -60.6 \\
$\mathrm{NMe}_{3}{ }^{+}$ & -75.0
\end{tabular}

${ }^{a}$ Energies were calculated at the G3(MP2)-RAD(+) level of theory and include scaled zero-point energy corrections.

distance of $2.7 \AA$. A similar situation is found for the $(\mathrm{MeO})(\mathrm{HO}) \mathrm{P} \cdot$ and $(\mathrm{MeS})(\mathrm{HO}) \mathrm{P}$ - radicals but not for the $\left(\mathrm{Me}_{2} \mathrm{~N}\right)(\mathrm{HO}) \mathrm{P} \cdot$ radical.

Phosphonyl-Hydroxyphosphinyl Tautomerism. In every case considered in Table 7, the RSE of a given hydroxyphosphinyl radical is greater than the RSE of the tautomeric phosphonyl radical appearing in Table 6 . The differences range from 15.3 (for $X=\mathrm{Me}_{3} \mathrm{Si}$ ) to $54.3 \mathrm{~kJ} \mathrm{~mol}^{-1}$ (for $\mathrm{X}=\mathrm{F}$ ). As well as comparing the differences in RSEs within each tautomeric pair, it is also possible to compare directly the absolute stabilities. The differences between the enthalpies of the $\mathrm{X}(\mathrm{HO}) \mathrm{P} \cdot$ radicals and those of the corresponding $\mathrm{XYP}(=\mathrm{O})$. radicals are listed in Table 8 .

For $\mathrm{X}=\mathrm{H}$, the two-coordinate radical $\mathrm{X}(\mathrm{HO}) \mathrm{P} \cdot$ is $36 \mathrm{~kJ}$ $\mathrm{mol}^{-1}$ more stable than the three-coordinate radical $\mathrm{H}(\mathrm{X}) \mathrm{P}(=\mathrm{O}) \cdot$. The same trend is found for every other $\mathrm{X}$ substituent in Table 8. This behavior is noteworthy. Earlier theoretical calculations have suggested that for the closed-shell parent species having $\mathrm{X}=\mathrm{H}$, the $-\mathrm{P}(\mathrm{OH})$ form is more stable ${ }^{45}$ however, the relative stabilities have been called into question more recently on the basis of complete basis set extrapolations employing the coupled-cluster series. ${ }^{46}$ Experimental observations in this case are equivocal. ${ }^{47}$ Otherwise, it is normally only in the presence of strongly electron-withdrawing $\mathrm{X}$ groups [e.g., $\left.\left(\mathrm{CF}_{3}\right)_{2} \mathrm{POH}\right]$ that the $-\mathrm{P}(\mathrm{OH})$ form is found experimentally to dominate. ${ }^{48}$ The presence of electron-withdrawing groups disfavors the $>\mathrm{P}(=\mathrm{O}) \mathrm{H}$ form due to the polar nature of the $\mathrm{P}=\mathrm{O}$ bond (which is more accurately described as $\mathrm{P}^{+}-\mathrm{O}^{-}$). For the radical species considered in Table 8, similar considerations must also play a role, as there is indeed an increased preference for the $-\mathrm{P}(\mathrm{OH})$ isomer of the radical when the $\mathrm{X}$ substituent is highly electron-withdrawing. [Such an effect cannot be solely due to increased stabilization of the $-\mathrm{P}(\mathrm{OH})$ form, since either $\sigma$ - or $\pi$-withdrawing $\mathrm{X}$ groups yield this result.] However, the two-coordinate radical is preferred even for the relatively electron-rich substituent, $\mathrm{Me}_{3} \mathrm{Si}$. It is likely that the tautomeric preference arises from the greater $\mathrm{p}$ character of the SOMO in the two-coordinate radical.

\section{Concluding Remarks}

Although hydroxyphosphinyl radicals $\mathrm{X}(\mathrm{HO}) \mathrm{P} \cdot$ are calculated to be more thermodynamically stable than their phosphonyl tautomers, it is questionable how this enhanced stability impacts on the radicals' chemistry. In synthetic scenarios, the $\mathrm{P}-\mathrm{H}$ parent compound that would give rise to a phosphonyl radical $\mathrm{X}(\mathrm{H}) \mathrm{P}(=\mathrm{O})$ • will in most cases exist preferentially as the $\mathrm{XYP}(=\mathrm{O}) \mathrm{H}$ tautomer. The isomerization of the initially formed phosphonyl radical to the hydroxyphosphinyl radical 
$\mathrm{X}(\mathrm{HO}) \mathrm{P} \cdot$ may not be fast enough to compete with alternative modes of reaction. An intramolecular tautomerization via a 1,2hydrogen shift is unlikely; we calculate that the isomerization of the $\mathrm{H}(\mathrm{HO}) \mathrm{P}(=\mathrm{O}) \cdot$ radical to the $(\mathrm{HO})(\mathrm{HO}) \mathrm{P} \cdot$ radical via this mechanism should have a prohibitively high barrier of $\Delta H_{0}^{\ddagger}=$ $143 \mathrm{~kJ} \mathrm{~mol}^{-1}$. Earlier calculations of high barriers to the corresponding isomerization in the closed-shell system have been reported: $\Delta E^{\ddagger} 290 \mathrm{~kJ} \mathrm{~mol}^{-1}$ at the $\mathrm{MP} 2 / 6-31 \mathrm{G}(\mathrm{d})$ level ${ }^{45 \mathrm{a}}$ and $284 \mathrm{~kJ} \mathrm{~mol}^{-1}$ at the $\mathrm{ACCD} / \mathrm{TZP}^{+}$level. ${ }^{45 \mathrm{~b}}$ A very recent report ${ }^{49}$ has suggested that under air initiation, secondary phosphine oxides $\mathrm{RH}_{2} \mathrm{P}(=\mathrm{O})$ add to alkenes $\mathrm{CH}_{2}=\mathrm{CHR}^{\prime}$ via a radical mechanism to give products of the type $\mathrm{R}^{\prime} \mathrm{CH}_{2} \mathrm{CH}_{2} \mathrm{P}(\mathrm{H})(\mathrm{R})(=\mathrm{O})$. However, it is not possible to discount the intermediacy of radicals $\mathrm{R}(\mathrm{OH}) \mathrm{P} \cdot$ in that case, because any initially formed hydroxyphosphine $\mathrm{R}^{\prime} \mathrm{CH}_{2} \mathrm{CH}_{2} \mathrm{P}(\mathrm{R})(\mathrm{OH})$ would be spontaneously converted to the four-coordinate product. We are currently investigating further the importance of the tautomeric radicals in the mechanistic chemistry of phosphorus-based chain carriers, with a view to designing efficient chain-carrier reagents.

Acknowledgment. We gratefully acknowledge useful discussions with Associate Professor Michael Sherburn, financial support from the Australian Research Council in the form of Centre of Excellence Funding, and generous allocations of computer time from the Australian Partnership for Advanced Computing and the Australian National University Supercomputer Facility.

Supporting Information Available: Geometries of the radicals and closed-shell hydrides are provided in the form of Gaussian archive entries in Table S1. This material is available free of charge via the Internet at http://pubs.acs.org.

\section{References and Notes}

(1) See, for example, (a) Roberts, B. P. Adv. Free Radical Chem. 1980, 6, 225-289. (b) Roberts, B. P.; Singh, K. J. Chem. Soc. 1980, 15491556. (c) Giles, J. R. M.; Roberts, B. P. J. Chem. Soc. 1981, 1211-1220. (d) Bentrude, W. G. Acc. Chem. Res. 1982, 15, 117-125. (e) Roberts, B. P. Tetrahedron Lett. 1983, 24, 3377-3380. (f) Power, P. P. Chem. Rev. 2003, 103, 789-809.

(2) See, for example, (a) Janssen, R. A. J.; Visser, G. J.; Buck, H. M. J. Am. Chem. Soc. 1984, 106, 3429-3437. (b) Cramer, C. J. J. Am. Chem. Soc. 1990, 112, 7965-7972. (c) Cramer, C. J. J. Am. Chem. Soc. 1991, 113, 2439-2447. (d) Cramer, C. J.; Gustafson, S. M. J. Am. Chem. Soc. 1993, 115, 9315-9316. (e) Cramer, C. J. Chem. Phys. Lett. 1993, 202, 297-302. (f) Cramer, C. J.; Lim, M. H. J. Phys. Chem. 1994, 98, 50245033. (g) Schiesser, C. H.; Wild, L. M. Aust. J. Chem. 1995, 48, 175-184. (h) Nguyen, M. T.; Creve, S.; Vanquickenborne, L. G. J. Phys. Chem. A 1997, 101, 3174-3181. (i) Lim, M.; Cramer, C. J. J. Phys. Org. Chem. 1998, 11, 149-154. (j) Hodgson, J. L.; Coote, M. L. J. Phys. Chem. A 2005, 109, 10013-10021.

(3) Marque, S.; Tordo, P. Top. Curr. Chem. 2005, 250, 43-76.

(4) Leca, D.; Fensterbank, L.; Lacôte, E.; Malacria, M. Chem. Soc. Rev. 2005, 34, 858-865.

(5) Davies, A. G.; Dennis, R. W.; Griller, D.; Ingold, K. U.; Roberts, B. P. Mol. Phys. 1973, 25, 989-991.

(6) Roberts, B. P.; Singh, K. J. Organomet. Chem. 1978, 159, 31-35.

(7) Majima, T.; Schnabel, W. J. Photochem. Photobiol., A 1989, 50, 31-39.

(8) Barton, D. H. R.; Jang, D. O.; Jaszberenyi, J. C. Tetrahedron Lett. 1992, 33, 5709-5712.

(9) Barton, D. H. R.; Jang, D. O.; Jaszberenyi, J. C. J. Org. Chem. 1993, $58,6838-6842$

(10) Gonzalez Martin, C.; Murphy, J. A.; Smith, C. R. Tetrahedron Lett. 2000, 41, 1833-1836.

(11) Jang, D. O.; Cho, D. H.; Chung, C.-M. Synlett 2001, 12, 19231924.

(12) Quin, L. D. A Guide to Organophosphorus Chemistry; WileyInterscience: New York, 2000; pp 12-15.

(13) Hehre, W. J.; Radom, L.; Schleyer, P. v. R.; Pople, J. A. Ab Initio Molecular Orbital Theory; Wiley: New York, 1986.
(14) Koch, W.; Holthausen, M. C. A Chemist's Guide to Density Functional Theory; Wiley-VCH: Weinheim, Germany, 2000.

(15) Frisch, M. J.; Trucks, G. W.; Schlegel, H. B.; Scuseria, G. E.; Robb, M. A.; Cheeseman, J. R.; Montgomery, J. A., Jr.; Vreven, T.; Kudin, K. N.; Burant, J. C.; Millam, J. M.; Iyengar, S. S.; Tomasi, J.; Barone, V.; Mennucci, B.; Cossi, M.; Scalmani, G.; Rega, N.; Petersson, G. A.; Nakatsuji, H.; Hada, M.; Ehara, M.; Toyota, K.; Fukuda, R.; Hasegawa, J.; Ishida, M.; Nakajima, T.; Honda, Y.; Kitao, O.; Nakai, H.; Klene, M.; Li, X.; Knox, J. E.; Hratchian, H. P.; Cross, J. B.; Bakken, V.; Adamo, C.; Jaramillo, J.; Gomperts, R.; Stratmann, R. E.; Yazyev, O.; Austin, A. J.; Cammi, R.; Pomelli, C.; Ochterski, J. W.; Ayala, P. Y.; Morokuma, K.; Voth, G. A.; Salvador, P.; Dannenberg, J. J.; Zakrzewski, V. G.; Dapprich, S.; Daniels, A. D.; Strain, M. C.; Farkas, O.; Malick, D. K.; Rabuck, A. D.; Raghavachari, K.; Foresman, J. B.; Ortiz, J. V.; Cui, Q.; Baboul, A. G.; Clifford, S.; Cioslowski, J.; Stefanov, B. B.; Liu, G.; Liashenko, A.; Piskorz, P.; Komaromi, I.; Martin, R. L.; Fox, D. J.; Keith, T.; Al-Laham, M. A.; Peng, C. Y.; Nanayakkara, A.; Challacombe, M.; Gill, P. M. W.; Johnson, B.; Chen, W.; Wong, M. W.; Gonzalez, C.; Pople, J. A. Gaussian 03, revision C.02; Gaussian, Inc.: Wallingford, CT, 2004

(16) Werner, H.-J.; Knowles, P. J.; Lindh, R.; Manby, F. R.; Schütz, M.; Celani, P.; Korona, T.; Rauhut, G.; Amos, R. D.; Bernhardsson, A.; Berning, A.; Cooper, D. L.; Deegan, M. J. O.; Dobbyn, A. J.; Eckert, F.; Hampel, C.; Hetzer, G.; Lloyd, A. W.; McNicholas, S. J.; Meyer, W. Mura, M. E.; Nicklass, A.; Palmieri, P.; Pitzer, R; Schumann, U.; Stoll, H.; Stone, A. J.; Tarroni, R.; Thorsteinsson, T. MOLPRO, version 2006.1, a package of ab initio programs; see http://www.molpro.net.

(17) Scott, A. P.; Radom, L. J. Phys. Chem. 1996, 100, 16502-16513.

(18) Coote, M. L.; Hodgson, J. L.; Krenske, E. H.; Wild, S. B. Heteroat. Chem. 2007, 18, 118-128.

(19) Henry, D. J.; Sullivan, M. B.; Radom, L. J. Chem. Phys. 2003 , $118,4849-4860$

(20) Henry, D. J.; Parkinson, C. J.; Mayer, P. M.; Radom, L. J. Phys. Chem. A 2001, 105, 6750-6756.

(21) Coote, M. L.; Henry, D. J. Macromolecules 2005, 38, 1415-1433.

(22) Wood, G. P. F.; Henry, D. J.; Radom, L. J. Phys. Chem. A 2003, 107, 7985-7990.

(23) Coote, M. L. J. Phys. Chem. A 2005, 109, 1230-1239.

(24) Coote, M. L.; Wood, G. P. F.; Radom, L. J. Phys. Chem. A 2002, $106,12124-12138$

(25) Coote, M. L. J. Phys. Chem. A 2004, 108, 3865-3872.

(26) Coote, M. L.; Pross, A.; Radom, L. In Fundamental World of Quantum Chemistry: A Tribute to the Memory of Per-Olov Löwdin; Brändas, E. J., Kryachko, E. J., Eds.; Kluwer-Springer: Dordrecht, The Netherlands, 2004; Vol. III, pp 563-579.

(27) Gómez-Balderas, R.; Coote, M. L.; Henry, D. J.; Radom, L. J. Phys. Chem. A 2004, 108, 2874-2883.

(28) Coote, M. L.; Krenske, E. H.; Lin, C. Y.; Louis, I.; Sherburn, M. $\mathrm{S}$. To be published.

(29) See, for example, Zipse, H. Top. Curr. Chem. 2006, 263, 163-189.

(30) Glendening, E. D.; Reed, A. E.; Carpenter, J. E.; Weinhold, F. NBO, version 3.1; Theoretical Chemistry Institute, University of Wisconsin: Madison, WI, 1996

(31) Hirao, T.; Saito, S.; Ozeki, H. J. Chem. Phys. 1996, 105, 3450-3457.

(32) Herzberg, G. Electronic Spectra and Electronic Structure of Polyatomic Molecules; Van Nostrand: New York, 1966.

(33) Begum, A.; Symons, M. C. R. J. Chem. Soc., Faraday Trans. 2 1973, $43-48$

(34) Martin, J. M. L.; de Oliveira, G. J. Chem. Phys. 1999, 111, 18431856

(35) Parthiban, S.; Martin, J. M. L. J. Chem. Phys. 2001, 114, 60146029. 1856

(36) Coote, M. L. J. Phys. Chem. A 2004, 108, 3865-3872.

(37) Gómez-Balderas, R.; Coote, M. L.; Henry, D. J.; Radom, L. J. Phys. Chem. A 2004, 108, 2874-2883.

(38) Coote, M. L.; Wood, G. P. F.; Radom, L. J. Phys. Chem. A 2002, 106, 12124-12138

(39) Berkowitz, J.; Ellison, G. B.; Gutman, D. J. Phys. Chem. 1994, 98, 2744-2765

(40) Berkowitz, J.; Curtiss, L. A.; Gibson, S. T.; Greene, J. P.; Hillhouse, G. L.; Pople, J. A. J. Chem. Phys. 1986, 84, 375-384.

(41) National Institute of Standards and Technology Computational Chemistry Comparison and Benchmark DataBase, Release 12. http:// srdata.nist.gov/cccbdb/ (Aug 2005). The relevant heats of formation contained in the database are taken from Gurvich, L. V.; Veyts, I. V.; Alcock, C. B. Thermodynamic Properties of Individual Substances, 4th ed.; Hemisphere: New York, 1989 and Chase, M. W., Jr.; Davies, C. A.; Downey, J. R., Jr.; Frurip, D. J.; McDonald, R. A.; Syverud, A. N. JANAF Thermochemical Tables, 3rd ed., Part I, Aluminum-Cobalt. J. Phys. Chem. Ref. Data, Suppl. 1985, 14, 1-926.

(42) Fossey, J.; Lefort, D.; Sorba, J. Free Radicals in Organic Chemistry; Wiley: Chichester, U.K., 1995; Chapter 8 .

(43) Bernardi, F.; Epiotis, N. D.; Cherry, W.; Schlegel, H. B.; Whangbo, M.-H.; Wolfe, S. J. Am. Chem. Soc. 1976, 98, 469-478. 
(44) See, for example, (a) Dobbs, A. J.; Gilbert, B. C.; Norman, R. O. C. J. Chem. Soc. A 1971, 124-135. (b) Dobbs, A. J.; Gilbert, B. C.; Norman, R. O. C. J. Chem. Soc., Perkin Trans 2 1972, 786-794. (c) Griller, D.; Nonhebel, D. C.; Walton, J. C. J. Chem. Soc., Perkin Trans. 2 1984, $1817-$ 1821. (d) Beckwith, A. L. J., Brumby, S. J. Chem. Soc., Perkin Trans 2 1987, 1801-1807. (e) Henry, D. J.; Beckwith, A. L. J.; Radom, L. Aust. J. Chem. 2003, 56, 429-436.

(45) See, for example, (a) Schmidt, M. W.; Yabushita, S.; Gordon, M. S. J. Phys. Chem. 1984, 88, 382-389. (b) Cramer, C. J.; Dykstra, C. E.; Denmark, S. E. Chem. Phys. Lett. 1987, 136, 17-21.
(46) Wesolowski, S. S.; Brinkmann, N. R.; Valeev, E. F.; Schaefer, H. F., III; Repasky, M. P.; Jorgensen, W. L. J. Chem. Phys. 2002, 116, 112-122.

(47) See, for example, (a) Ahmad, I. K.; Ozeki, H.; Saito, S. J. Chem. Phys. 1999, 110, 912-917. (b) Withnall, R.; Hawkins, M.; Andrews, L. J. Phys. Chem. 1986, 90, 575-579. (c) Withnall, R.; Andrews, L. J. Phys. Chem. 1987, 91, 784-797. (d) Withnall, R.; Andrews, L. J. Phys. Chem. 1988, 92, 4610-4619.

(48) Griffiths, J. E.; Burg, A. B. J. Am. Chem. Soc. 1962, 84, 3442-3450. (49) Hirai, T.; Han, L.-B. Org. Lett. 2007, 9, 53-55. 